\title{
ИССЛЕДОВАНИЕ СКВАЖИН НОВЫХ МЕСТОРОЖДЕНИЙ МАНАВСКОЙ НЕФТИ
}

\author{
${ }^{1}$ Натела Хецуриани, doctor \\ ${ }^{2}$ Есма Уиараули, PhD \\ ${ }^{3}$ Мадлена Чхаидзе, $M S$ \\ ${ }^{4}$ Тамар Шатакишвили, $M S$ \\ ${ }^{5}$ Мака Копалешивили, $M S$
}

Тбилиси, Грузия, ТГУ, Институт физической и органической химии им. Петре Меликишвили, Лаборатория химия нефти

${ }^{1}$ Заведующий лаборатории, главный научный сотрудник;

${ }^{2}$ Старший научный сотрудник;

${ }^{3}$ научный сотрудник;

${ }^{4}$ научный сотрудник;

${ }^{5}$ научный сотрудник;

DOI: https://doi.org/ 10.31435/rsglobal_ws/31102018/6179

\section{ARTICLE INFO}

Received: 18 August 2018

Accepted: 10 October 2018

Published: 31 October 2018

\section{KEYWORDS}

crude oil, naphtha,

diesel fraction,

IR -spectrometry, gas-chromatography.

\begin{abstract}
An investigation of oils from new wells of Manavi oil deposit was carried out. Physical and chemical and geochemical parameters, as well as functional groups were determined by IR spectrometry. Using simulative chromatographic distillation of oil from the \#12 well naphtha

$35-180{ }^{\circ} \mathrm{C}$ and diesel fractions were obtained. Individual paraffinic, naphthenic and aromatic hydrocarbons were identified in naphtha by gas chromatographic method and distribution of individual n-paraffinic hydrocarbons in urea concentrate was determined in diesel fraction. The results of the investigation show that due to low content of sulfur, tarasphaltenic compounds and high yield of light fractions the Manavi oil can be recognized as a high quality paraffinic type of oil. Physical and chemical characteristics, chemical nature and high yield of light fractions outline a good perspective for usage of Manavi deposit oil as a raw material for production of commodity petroleum products like high quality organic solvents, aviation and diesel fuels and various petroleum oils.
\end{abstract}

Citation: Натела Хецуриани, Есма Ушараули, Мадлена Чхаидзе, Тамар Шатакишвили, Мака Копалеишвили (2018) Issledovanie Skvajin Novih Mestorojdenii Manavskoi Nefti. World Science. 10(38), Vol.1. doi: $10.31435 /$ rsglobal_ws/31102018/6179

Copyright: (C) 2018 Натела Хецуриани, Есма Ушараули, Мадлена Чхаидзе, Тамар Шатакишвили, Мака Копалеишвили. This is an open-access article distributed under the terms of the Creative Commons Attribution License (CC BY). The use, distribution or reproduction in other forums is permitted, provided the original author(s) or licensor are credited and that the original publication in this journal is cited, in accordance with accepted academic practice. No use, distribution or reproduction is permitted which does not comply with these terms.

Введение. Основным энергоносителем в мировой экономике является нефть, продукция которой используется всеми другими отраслями промышленности, и которая обеспечивает $1 / 3$ мирового спроса не энергоресурсы. Мировые запасы нефти по данным 2018 года составляют 7471,5млрд баррелей на суше и 160млрд баррелей на морском дне.

В 21-м веке одной из главнейших проблем среди стоящих перед человечеством вызовов является решение вопроса энергобезопасности. Страны, которые имеют достаточные ресурсы нефти и газа, могут обеспечить свою энергобезопасность, развитие экономики и упрочить свою независимость. Грузия по своему геологическому строению одновременно принадлежит к двум нефтегазосодержащим территориям: к черноморской области и к каспийской провинции. По расчетам иностранных и грузинских специалистов прогнозные ресурсы нефти в Грузии составляют 
2млрд 350млн тонн, а газа - 180млрд м. Даже в случае освоения 40-50\% этого потенциального ресурса бюджет страны получит прибыль в несколько сотен миллиардов долларов.

Исследованиями установлено, что по физико-химическим показателям нефти Грузии принадлежат к уникальным, малосернистым, высококачественным, и с точки зрения переработки являются довольно интересным сырьем. Исследования этой нефти показали, что в Грузии встречаются нефти почти всех известных типов отличающиеся друг от друга по своей химической природе (парафиновые, нафтеновые, нафтеноароматические, ароматический и т. д.). Посредством изучения нефти и их физико-химических и геохимических показателей едиными комплексными методами можно планировать производство товарных нефтепродуктов энергетического назначения для местной промышленности и сельского хозяйства, чему придается огромное значение для установления энергетических ресурсов страны и рационального управления ими [1-5].

Целью работы являлось исследование новых скважин Манавской нефти для их паспортизации. Указанные месторождения находятся южнее Кахетинского хребта на расстоянии 60 км от Тбилиси. Они расположены к севера- югу от купола Ниноцминдского нефтеносного антиклина с соответствующими осадочным структурами, состоящих из нефтесодержащих верхнемеловых палеогенных осадков. Добычу нефти на скважинах №11 и №12 осуществляет компания „Canargo Energy Corporation”. Запасы скважины составляют 130млн баррелей нефти и 59млрд футов газа 2C (NSA). Интервал перфорации 4680-4953м. Физико-химические характеристики сырой нефти месторождения Манави приведены в таблице 1.

Таблица 1. Физико-химические характеристики нефти Манави

\begin{tabular}{|c|c|c|c|}
\hline \multirow[t]{2}{*}{ Показатели } & \multicolumn{2}{|c|}{ Скважина манавской нефти } & \multirow[t]{2}{*}{ Метод исследования } \\
\hline & № 11 & № 12 & \\
\hline Плотность $20^{0} \mathrm{C}$, кг $/ \mathrm{M}^{3}$ & 826,0 & 822,5 & ASTM D052 \\
\hline Плотность $15^{0} \mathrm{C}$, кг $/ \mathrm{M}^{3}$ & 829,6 & 826,5 & ASTM D4052 \\
\hline${ }^{0} \mathrm{API}$ & 39.6 & 40,0 & ASTM D1298-12b \\
\hline Температура застывания, ${ }^{0} \mathrm{C}$ & 3 & 0 & ASTM D 5853 \\
\hline Кинематическая вязкость, ССт & 3,4 & 3,15 & ASTM D 445 \\
\hline Содержание серы, \% & 0,18 & 0,17 & ASTM D 4294 \\
\hline Смолы, \% & 7,07 & 8,12 & ASTM D 2007 \\
\hline Асфальтены, \% & 1,86 & 2,7 & ASTM D 3279 \\
\hline Содержание парафинов, \% & 6,5 & 6,2 & ASTM UOP46 \\
\hline $\begin{array}{l}\text { Содержание механических } \\
\text { примесей,\% }\end{array}$ & 0,02 & 0,01 & ASTM D 473 \\
\hline \multicolumn{4}{|c|}{ Температура вспышки, ${ }^{0} \mathrm{C}$} \\
\hline В открытом тигеле & -3 & -2 & ASTM D 92 \\
\hline В закрытом тигеле & -6 & -8 & ASTM D 93 \\
\hline Выход светлых фракций $360^{\circ} \mathrm{C}, \%$ & 65,0 & 67,4 & ASTM D 2892 \\
\hline
\end{tabular}

Исследуемая нефть характеризуется средней плотностью, высоким выходом легких фракций $(68 \%)$ и низким содержанием серы и смолисто-асфальтеновых соединений $(8,92 \%)$, содержание парафинов - 6,1\%. Имитационная полная перегонка нефти выполнена на хроматографе Sim Dis, Auto System XL, фирма Perkin Elmer соотвествено ASTM D 2887стандартом [6]. Исследуемая нефть характеризуется высоким содержанием легкой фракции, остаток свыше $500^{\circ} \mathrm{C}$ составляет 12,5\%. На рисунке 1 приведена кривая перегонки Манавской нефти. 


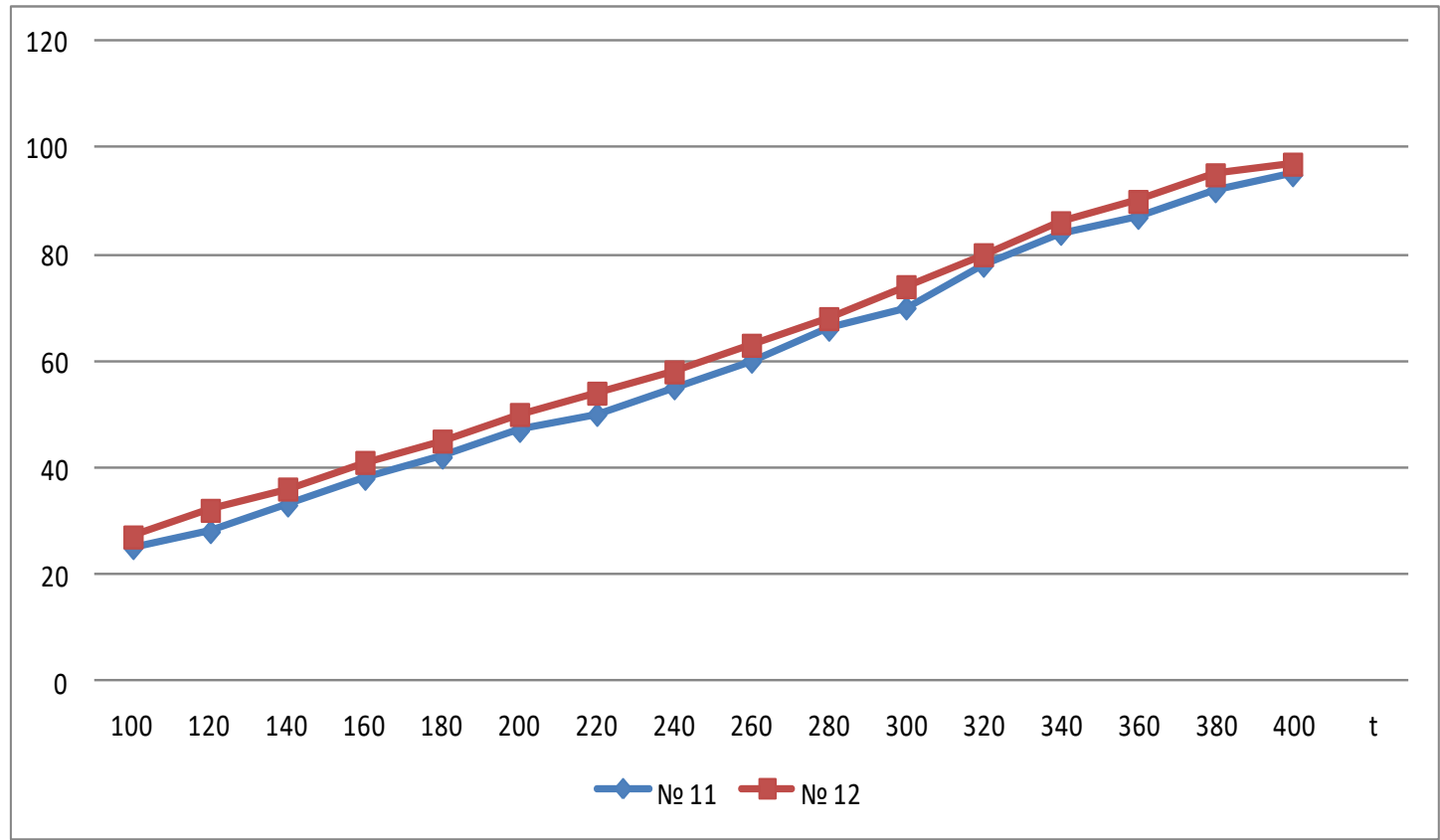

Рис. 1. Кривые разгонки Манавской нефти скв. №11 и скв.№12

ИК-спектрометрический анализ нефти новых скважин, проведенный на спектрометре Perkin Elmer Spectrum, модель 10.4.2., показал, что ИК-спектры скважин практически идентичны. Интенсивность полос поглощения 721,4 $\mathrm{cm}^{-1}$ и $1377 \mathrm{~cm}^{-1}$ характеризует содержание метильных и метиленовых групп парафиновых углеводородах, $2924 \mathrm{~cm}^{-1}$ и $2852 \mathrm{~cm}^{-1}$ (метильная) и $2854 \mathrm{~cm}^{-1}$ и $2924 \mathrm{~cm}^{-1}$ (метиленовая). Наличие в спектре полосы $1600 \mathrm{~cm}^{-1}$ характеризует содержание ароматических углеводородов в нефти. Такой результат, вместе с физикохимическими показателями исследуемой нефти, говорит о том, что нефти новых скважин Манавского месторождения имеют одинаковый химический состав. Данная нефть относится к парафинистому типу.

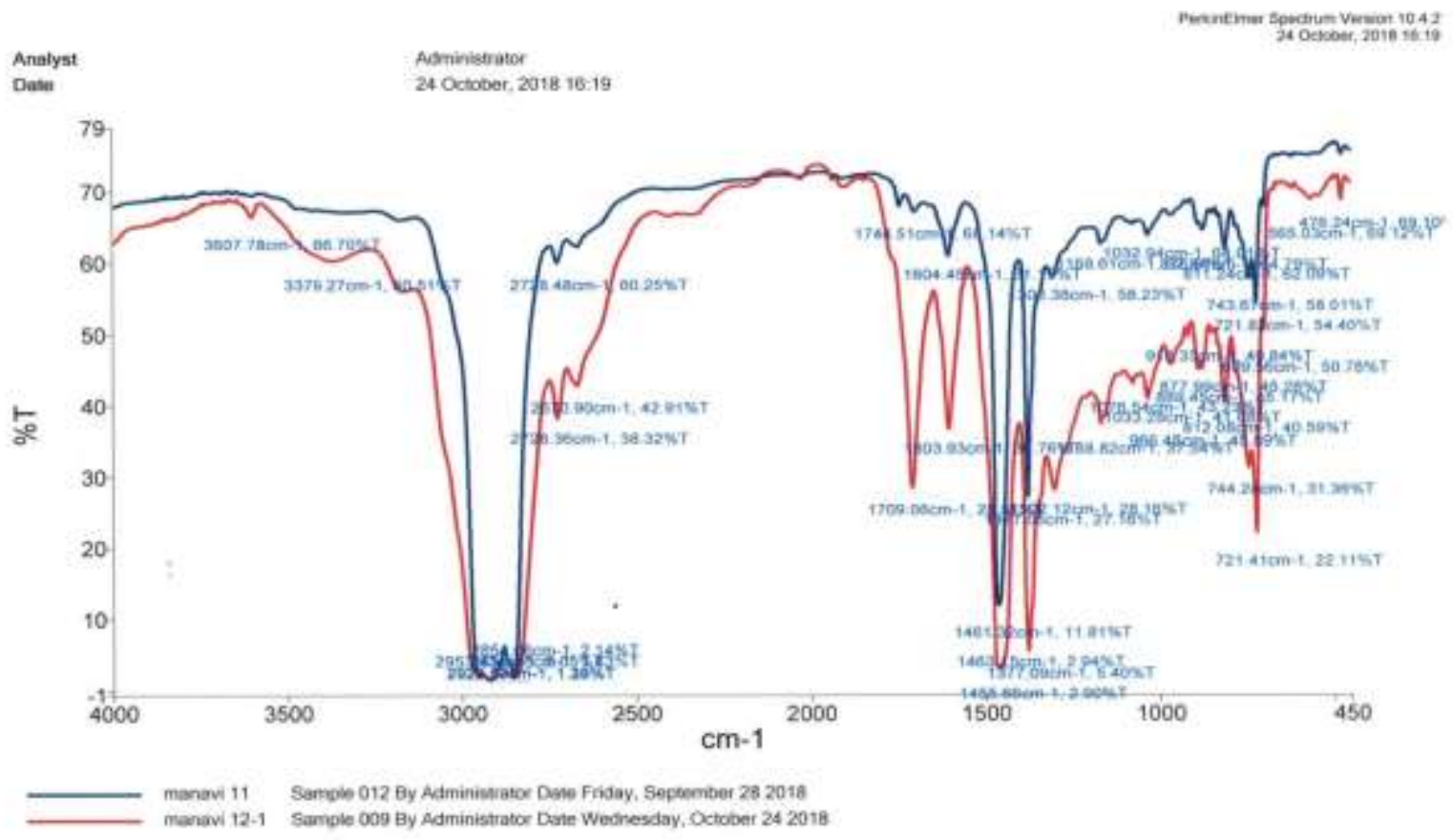

Рис. 2. ИК-спектры Манавской нефтии 
Из результатов исследования выясняется, что благодаря низкому содержанию серы, смолисто-асфальтеновых соединений и высокому выходу легких фракций Манавская нефть представляет собой высококачественную нефть парафинового типа.

Выделенная из Манавской нефти фракция нефти $\left(35-180^{\circ} \mathrm{C}\right)$ была изучена газохроматографическим методом - "PON A"[7]. Было определены элементный и групповой углеводородный состав, молекулярная масса, относительная плотность, давление насыщенных паров и октановое число (таблица 2).

Таблица 2. Характеристика фракции нефти

\begin{tabular}{|c|c|c|c|c|c|c|c|c|}
\hline \multirow{2}{*}{\multicolumn{4}{|c|}{\begin{tabular}{|l|} 
Характеристики \\
Плотность, кг/м ${ }^{3}$
\end{tabular}}} & \multirow{2}{*}{\multicolumn{2}{|c|}{$\begin{array}{c}\text { Величина } \\
736,0\end{array}$}} & \multicolumn{3}{|c|}{ Групповой состав } \\
\hline & & & & & & Виды групп & $\begin{array}{l}\text { Выход, } \\
\text { массовые \% }\end{array}$ & $\begin{array}{l}\text { Выход, } \\
\text { объемные \% }\end{array}$ \\
\hline \multicolumn{4}{|c|}{ Молекулярная масса } & \multicolumn{2}{|c|}{101,998} & Парафин & 24,027 & 25,972 \\
\hline \multicolumn{4}{|c|}{ Давление насыщенного пара, psi } & \multicolumn{2}{|c|}{1,7} & н-Парафин & 27,531 & 29,344 \\
\hline \multicolumn{4}{|c|}{ Октановое число } & \multicolumn{2}{|c|}{73,51} & Олефины & - & - \\
\hline \multirow[t]{2}{*}{ Перегонка } & Н.К. & $10 \%$ & $50 \%$ & $90 \%$ & к.к. & Нафтены & 32,231 & 30,932 \\
\hline & $31^{\circ} \mathrm{C}$ & $70^{\circ} \mathrm{C}$ & $110^{\circ} \mathrm{C}$ & $156^{\circ} \mathrm{C}$ & $200^{\circ} \mathrm{C}$ & Ароматика & 15,753 & 13,362 \\
\hline \multicolumn{4}{|c|}{ Содержание С } & \multicolumn{2}{|c|}{86,118} & Неизвестно & 0,459 & 0,399 \\
\hline \multicolumn{4}{|c|}{ Содержание Н } & \multicolumn{2}{|c|}{13,882} & Сумма & 100,0 & 100,0 \\
\hline
\end{tabular}

Октановое число нафты-75,5, является высоким показателем для исходной фракции, что вызвано оптимальным соотношением парафиновых, изопарафиновых, нафтеновых и ароматических углеводородов. Идентифицированы также индивидуальные парафиновые, нафтеновые и ароматические углеводороды и их производные (таблица 3 ).

Таблица 3. Идентифицированные соединения

\begin{tabular}{|c|c|l|c|c|c|}
\hline RT,min & Index & Component & Mass.\% & Vol\% & Mol\% \\
\hline 1 & 2 & 3 & 4 & 5 & 6 \\
\hline 8.221 & 359.7 & n-butane & 0.689 & 0.880 & 1.215 \\
\hline 9.547 & 407.7 & i-pentane & 1.531 & 1.826 & 2.174 \\
\hline 10.267 & 427.5 & n-pentane & 2.472 & 2.917 & 2.174 \\
\hline 11.624 & 456.4 & 2,2-dimethylbutane & 0.159 & 0.182 & 0.190 \\
\hline 13.136 & 480.0 & 2,3-dimethylbutane & 0.946 & 1.057 & 1.125 \\
\hline 14.229 & 484.0 & 2-metylpentane & 2.090 & 2.365 & 2.485 \\
\hline 15.331 & 494.0 & 3-metylpentane & 1.440 & 1.602 & 1.712 \\
\hline 17.173 & 511,7 & n-hexane & 4.201 & 4.707 & 4.995 \\
\hline 17.401 & 539.5 & 2,2-dimetylpentane & 0.255 & 0.279 & 0.260 \\
\hline 17.696 & 543.8 & methylcyclopentane & 3.133 & 3.093 & 3.815 \\
\hline 20.072 & 546.6 & 2,4-dimethylpentane & 0.245 & 0.289 & 0.250 \\
\hline 20.709 & 574.9 & Benzene & 2.391 & 2.010 & 3.137 \\
\hline 21.539 & 581.6 & cyclohexane & 4.085 & 3.877 & 4.973 \\
\hline 21.763 & 590.0 & 2-methylhexane & 1.632 & 1.778 & 1.669 \\
\hline 22.600 & 592.1 & 2,3-dimethylpentane & 0.554 & 0.589 & 0.567 \\
\hline 23.475 & 596.0 & 3-methylhexane & 0.523 & 0.512 & 0.546 \\
\hline 23.848 & 600.0 & 1c,3-dimethylcyclopentane & 1.852 & 1.991 & 1.893 \\
\hline 24.216 & 609.8 & 1t,3-dimethylcyclopentane & 0.810 & 0.804 & 0.846 \\
\hline 25.981 & 613.8 & 3-ethylpentane & 0.949 & 0.937 & 0.991 \\
\hline 29.381 & 617.6 & n-heptane's & 1.355 & 1.434 & 1.385 \\
\hline 29.744 & 635.2 & Methylcyclohexane & 5.096 & 5.507 & 5.211 \\
\hline 31.317 & 664.4 & 2,2-dimethylhexane & 8.754 & 8.408 & 9.136 \\
\hline 31.712 & 667.7 & ethylcyclopentane & 0.565 & 0.601 & 0.507 \\
\hline 31.712 & 682.7 & 2,4-dimethylhexane & 0.721 & 0.695 & 0.752 \\
\hline 32.895 & 690.0 & 1c, 2t,4-trimethylcyclopentane & 0.320 & 0.338 & 0.287 \\
\hline 34.187 & 700.0 & 1t,2c,3-trimethylcyclopentane & 0.553 & 0.536 & 0.505 \\
\hline 36.344 & 712.6 & Toluene & 0.555 & 0.532 & 0.506 \\
\hline
\end{tabular}


Продолжение таблицы 3

\begin{tabular}{|c|c|c|c|c|c|}
\hline 1 & 2 & 3 & 4 & 5 & 6 \\
\hline 36.819 & 715.3 & 2,3-dimethylhexane & 4.711 & 4.015 & 5.239 \\
\hline 37.032 & 716.5 & 2-methyl-3-ethylpentane & 0.240 & 0.249 & 0.215 \\
\hline 38.061 & 722.0 & 2-methylheptane & 0.324 & 0.336 & 0.291 \\
\hline 38.331 & 723.5 & 4-methylheptane & 2.160 & 2.287 & 1.937 \\
\hline 39.539 & 729.8 & heptane's & 0.560 & 0.558 & 0.503 \\
\hline 39.901 & 731.5 & $1 \mathrm{c}, 2 \mathrm{t}, 3$-trimethylcyclopentane & 1.387 & 1.452 & 1.244 \\
\hline 40.253 & 733.4 & 3-methylhepane & 2.393 & 2.295 & 2.185 \\
\hline 41.347 & 738.7 & 3-ethylhexane & 0.952 & 0.986 & 0.854 \\
\hline 42.035 & 742.0 & 2,2,5-trimethylhexane & 0,395 & 0.375 & 0.361 \\
\hline 42.477 & 744.1 & 3c-ethylmethylcyclopentane & 0.181 & 0.189 & 0.145 \\
\hline 42.747 & 745.4 & 3t-ethylmethylcyclopentane & 0.387 & 0.375 & 0.355 \\
\hline 43.765 & 750.0 & 2t-ethylmethylcyclopentane & 1.216 & 1.166 & 1.110 \\
\hline 45.077 & 755.9 & n-octane & 5.058 & 5.320 & 4.537 \\
\hline 45.339 & 757.0 & 1c,4-dimethylcyclohexane & 0.667 & 0.630 & 0.609 \\
\hline 50.256 & 777.1 & 2,2,3-trimethylhexane & 0.223 & 0.207 & 0.204 \\
\hline 50.512 & 778.1 & 2,4-dimethylheptane & 0.360 & 0.368 & 0.288 \\
\hline 51.835 & 783.1 & 4,4- dimethylheptane & 2.817 & 2.696 & 2.287 \\
\hline 53.051 & 787.5 & 1,1,3- dimethylcyclohexane & 0.738 & 0.763 & 0.590 \\
\hline 53.608 & 789.5 & ethylbenzene & 0.601 & 0.621 & 0.480 \\
\hline 56.629 & 800.0 & 4,4-dimethylheptane & 0.216 & 0.223 & 0.173 \\
\hline 57.120 & 801.8 & 1,3-dimethylbenzene & 0.490 & 0.460 & 0.398 \\
\hline 57.611 & 803.5 & 1,3-dimethylbenzene & 0.800 & 0.682 & 0.772 \\
\hline 59.413 & 809.8 & \#12Benzene & 0.720 & 0.682 & 0.584 \\
\hline 60.245 & 812.6 & 1,3-dimethylbenzene & 2.922 & 2.499 & 2.820 \\
\hline 60.485 & 813.4 & 1,4-dimethylbenzene & 0.757 & 0.649 & 0.730 \\
\hline 60.691 & 814.1 & 1c, 2t,4t-trimethylcyclohexane & 0.288 & 0.273 & 0.234 \\
\hline 61.688 & 817.3 & 4-methyloctane & 0.547 & 0.561 & 0.437 \\
\hline 61.976 & 818.3 & 2-methyloctane & 0.748 & 0.774 & 0.597 \\
\hline 63.371 & 822.8 & 3-ethylheptane & 0.255 & 0.259 & 0.204 \\
\hline 63.672 & 823.7 & 3-methyloctane & 0.883 & 0.906 & 0.705 \\
\hline 65.965 & 830.8 & 1,2- dimethylbenzene & 1.254 & 1.053 & 1.211 \\
\hline 70.197 & 843.2 & n-nonane & 3.753 & 3.864 & 2.998 \\
\hline 70.715 & 844.7 & 1,1- methylethylcyclohexane & 0.457 & 0.419 & 0.371 \\
\hline 73.789 & 853.1 & i-propylcyclohexane & 0.166 & 0.153 & 0.135 \\
\hline 75.195 & 856.8 & 2,4-dimethyloctane & 0.871 & 0.886 & 0.627 \\
\hline 75.947 & 858.8 & 2,6- dimethyloctane & 0.290 & 0.295 & 0.209 \\
\hline 76.693 & 860.8 & 2,5- dimethyloctane & 0.640 & 0.648 & 0.461 \\
\hline 77.901 & 863.8 & 3,3-dimethyloctane & 0.304 & 0.304 & 0.219 \\
\hline 79.565 & 868.0 & 1,3-methylethylbenzene & 0.462 & 0.395 & 0.394 \\
\hline 79.864 & 868.7 & 1,4-methylethylbenzene & 0.300 & 0.257 & 0.256 \\
\hline 80.816 & 871.0 & 1,3,5-trimethyllbenzene & 0.243 & 0.208 & 0.207 \\
\hline 81.232 & 872.1 & 2,3-dimethyloctane & 0.322 & 0.322 & 0.232 \\
\hline 82.328 & 874.7 & 1,2- methylethylbenzene & 0.197 & 0.165 & 0.168 \\
\hline 82.616 & 875.4 & 2-methylnonane & 0.388 & 0.395 & 0.280 \\
\hline 84.088 & 878.8 & 3-methylnonane & 0.180 & 0.181 & 0.130 \\
\hline 84.579 & 880.0 & 1,2,4-tr methylethylbenzene & 0.925 & 0.780 & 0.789 \\
\hline 84.579 & 880.0 & 1,2,4-trimethyllbenzene & 1.872 & 1.895 & 1.348 \\
\hline 86.739 & 884.9 & n-decane & 0.247 & 0.204 & 0.211 \\
\hline 88.440 & 888.7 & 1,2,3-trimethylbenzene & 0.367 & 0.317 & 0.281 \\
\hline 89.861 & 891.8 & 1,4-methyl-i-propylbenzene & 0.218 & 0.188 & 0.166 \\
\hline 98.643 & 923.3 & n-undecane & 0.886 & 0.880 & 0.581 \\
\hline 116.779 & 1000.0 & 2-methylnaphtalyne & 0.175 & 0.127 & 0.125 \\
\hline
\end{tabular}


В таблице 4 представлены физико-химические показатели дизельных фракций с разной температурой кипения.

Таблица 4. Физико-химические показатели дизельных фракций

\begin{tabular}{|c|c|c|c|c|c|c|}
\hline Фракция & Выход, \% & $\mathrm{n}_{\mathrm{D}}^{20}$ & $\begin{array}{c}\text { Плотность } \\
20^{0} \mathrm{C}, \text { кг } / \mathrm{M}^{3}\end{array}$ & $\begin{array}{c}\text { Кинематическая } \\
\text { вязкость, сСт }\end{array}$ & $\begin{array}{c}\text { Дизельный } \\
\text { индекс }\end{array}$ & $\begin{array}{c}\text { Цетановое } \\
\text { число }\end{array}$ \\
\hline \multicolumn{7}{|c|}{ Манавская нефть, скважина № 11} \\
\hline $140-320^{\circ} \mathrm{C}$ & 42.1 & 1.4528 & 814.2 & 2.61 & 64.4 & 57,0 \\
\hline $140-350^{\circ} \mathrm{C}$ & 47.0 & 1.4560 & 820.8 & 3.2 & 63.3 & 55,0 \\
\hline $180-320^{\circ} \mathrm{C}$ & 33.0 & 1.4542 & 816.7 & 3.0 & 63.6 & 56.0 \\
\hline $180-350^{\circ} \mathrm{C}$ & 37.0 & 1.4650 & 834.3 & 4.5 & 64.7 & 50,6 \\
\hline \multicolumn{7}{|c|}{ Манавкая нефть, скважина № 12} \\
\hline $140-320^{\circ} \mathrm{C}$ & 42.0 & 1.4580 & 819.2 & 2.8 & 64.7 & 58.0 \\
\hline $140-350^{\circ} \mathrm{C}$ & 49.0 & 1.4640 & 822.3 & 3.3 & 63.5 & 55.60 \\
\hline $180-320^{\circ} \mathrm{C}$ & 34.1 & 1.4633 & 817.0 & 3.2 & 63.8 & 56.4 \\
\hline $180-350^{\circ} \mathrm{C}$ & 40.0 & 1.4682 & 835.0 & 4.6 & 61.6 & 51.8 \\
\hline
\end{tabular}

Исследование показало, что с повышением температуры кипения дизельной фракции повышается показатель преломления, плотность и кинематическая вязкость. Фракции характеризуются высоким дизельным индексом и цетановым числом. Карбамидных концентратах дизельных фракции газожидкостным хроматографическим методом изучено распределение н-парафиновых углеводородов во фракции $180-320^{\circ} \mathrm{C}$ (таблица 5).

Таблица 5. Парафиновые углеводороды

\begin{tabular}{|l|c|c|c|c|}
\hline \multicolumn{2}{|l|}{ Наименования углеводорода } & \multirow{2}{*}{$\begin{array}{l}\text { Молекулярная } \\
\text { масса, г/моль }\end{array}$} & \multicolumn{2}{l|}{ Относительная концентрация } \\
\cline { 3 - 5 } & & 164.40 & Манави №11 & Манави №12 \\
\hline Nonane & $\mathrm{C}_{9} \mathrm{H}_{20}$ & 142.29 & 2.14 & 1.33 \\
\hline Decane & $\mathrm{C}_{10} \mathrm{H}_{22}$ & 156.31 & 5.86 & 3.80 \\
\hline Undecane & $\mathrm{C}_{11} \mathrm{H}_{24}$ & 170.34 & 8.61 & 7.60 \\
\hline Dodecane & $\mathrm{C}_{12} \mathrm{H}_{26}$ & 18.40 & $1 ., 87$ & 9.33 \\
\hline Tridecane & $\mathrm{C}_{13} \mathrm{H}_{28}$ & 19.39 & 1.40 & 10.00 \\
\hline Tetradecane & $\mathrm{C}_{14} \mathrm{H}_{30}$ & 21.42 & 10.37 & 9.88 \\
\hline Pentadecane & $\mathrm{C}_{15} \mathrm{H}_{32}$ & 22.41 & 8.77 & 7.26 \\
\hline Hexadecane & $\mathrm{C}_{16} \mathrm{H}_{34}$ & 240.48 & 7.80 & 7.05 \\
\hline Heptadecane & $\mathrm{C}_{17} \mathrm{H}_{36}$ & 254.5 & 6.61 & 6.73 \\
\hline Octadecane & $\mathrm{C}_{18} \mathrm{H}_{38}$ & 268.52 & 5.70 & 4.87 \\
\hline Nonadecane & $\mathrm{C}_{19} \mathrm{H}_{40}$ & 282.55 & 4.78 & 4.24 \\
\hline Eicosane & $\mathrm{C}_{20} \mathrm{H}_{42}$ & 296.58 & 4.21 & 4.76 \\
\hline Heneicosane & $\mathrm{C}_{21} \mathrm{H}_{44}$ & 310.60 & 3.98 & 4.33 \\
\hline Docosane & $\mathrm{C}_{22} \mathrm{H}_{46}$ & 324.38 & 3.88 & 3.70 \\
\hline Tricosane & $\mathrm{C}_{23} \mathrm{H}_{48}$ & 338.65 & 2.65 & 2.73 \\
\hline Tetracosane & $\mathrm{C}_{24} \mathrm{H}_{50}$ & 352.69 & 1.20 & 1.70 \\
\hline Pentacosane & $\mathrm{C}_{25} \mathrm{H}_{52}$ & 366.72 & 0.79 & 1.36 \\
\hline Hexacosane & $\mathrm{C}_{26} \mathrm{H}_{54}$ & & & \\
\hline
\end{tabular}

В таблице представлены $\mathrm{C}_{9}-\mathrm{C}_{26}$ Н-парафиновые углеводороды, в которой относительно высокой концентрацией отличаются алканы $\mathrm{C}_{11}-\mathrm{C}_{17}(7,8-10,8 \%)$, в максимальном количестве содержится тетрадекан $\left(\mathrm{C}_{14} \mathrm{H}_{30}\right)$.

Изучено также распределение микроэлементов V, Fe, Ni, Co, Mo, Cu, Pb, Sn, Zn, Sr, Ba, Ti. Микроэлементы выделены разработанным в лаборатории химии нефти методом “Фотохимическим способом выделения концентрата зольных элементов из нефтей и нефтепродуктов”, который нашел широкое применение и в других научно-исследовательских организациях. Сравнение физико-химических характеристик и выходов легких фракций нефти новых скважин показывает, что они практически идентичны. Распределение микроэлементов и полученное соотношение $\mathrm{V} / \mathrm{Ni}<1$ показывают, что эти нефти относятся к третичным типам нефти, что объясняется условиями накопления исходного органического вещества и соответствующим геохимическим происхождением[8]. 
Результаты исследования. Исследовались нефти новых скважин манавского месторождения. Были определены физико-химические и геохимические показатели, а также функциональные группы ИК-спектрометрическим методом. Имитационной хроматографической разгонкой нефти скважины 12 выделены нефть $35-180^{\circ} \mathrm{C}$ и дизельные фракции. Газохроматографическим методом в нефти идентифицированы индивидуальные углеводороды парафинового, нафтенового и проматического рядов и установлено распределение индивидуальных н-парафиновых углеводородов в карбамидном концентрате дизельной фракции. Результаты исследования показывают, что благодаря низкому содержанию серы, смолисто-асфальтеновых соединений и высокому выходу легких фракций манавская нефть представляет собой высококачественную нефть парафинового типа. Физико-химические характеристики, химическая природа и высокий выход светлых фракций намечает хорошую перспективу использования нефти Манавского месторождения как сырья для получения товарных нефтепродуктов энергетического назначения - бензины, качественные органические растворители, авиационные и дизельные топлива и различные нефтяные масло для местной промышленности и сельского хозяйства.

\section{ЛИТЕРАТУРА}

1. Химия нефти и газа. А. И.Богомолов, А. А.Гайле и др., Издание: Химия, 1995, 448c. ISBN: 5-7245$1023-5$.

2. Современные методы исследование нефтей, Ленинград «Недра», 1984, 430с.

3. N. Khetsuriani, E. Usharauli, E. Topuria, I. MchedliShvili. Use of mass-spectrometry for investigation of aromatic structure of high-boiling compounds of oil. IX International massspectrometry conferece in Petrochemistry, ecology and food Chemistry "Petromass2011". Moscow, 2011, pp.128-131.

4. James G. Speight. Handbook of Petroleum Analysis. First published: February 2015, 368 pages. ISBN 978-1118369265. DOI: 10.1002/9781118986370.

5. V.G.Tsitsishvili, N.T.Khetsuriani. Georgian Crude Oil and Bitumen Deposits. Proceedings of the International Mass Spectrometry Conference on Petrochemistry and Environmental "PETROMASS2014", 2014, 1-4 September, Tbilisi, Georgia, pp.13-14.

6. ASTM D2887.Standard Test for Boiling Range Distribution of Petroleum Fraction by GasChromatography.

7. ASTM D 3710 Standard Test Method for Boiling Range Distribution of Gasoline and Gasoline Fractions by Gas-Chromatography.

8. N.Khetsuriani, E.Usharauli, K.Goderdzishvili, E.Topuria, M.Chchaidze, V.Tsitsishvili. Investigation of new Wells of SatskhenisiGrude Oil. Proceedings of the Georgian Natinal Academy of Sciences, 2016, \#4, v.42, pp.501-503. 